\title{
Abordagem do tema do aborto no ensino de graduação na perspectiva das enfermeiras recém-graduadas
}

\author{
Approaching the topic of abortion in undergraduate education from the perspective of newly graduated nurses \\ Enfoque del tema del aborto en la enseñanza de graduación en la perspectiva de enfermeras recién graduadas
}

\author{
Mariana Santana Schroeter'; Adriana Lenho de Figueiredo Pereira"
}

\begin{abstract}
RESUMO
Objetivo: descrever a abordagem do tema do aborto no ensino da graduação e seus nexos com a formação crítica na perspectiva das enfermeiras recém-graduadas. Método: pesquisa qualitativa realizada com 26 enfermeiras recém-graduadas e matriculadas em programas de residência no município do Rio de Janeiro. As entrevistas individuais ocorreram no período de abril a julho de 2016, sendo analisadas pela hermenêutica-dialética e com base referencial de Paulo Freire. O estudo respeitou as normas éticas e obteve por comitê de ética. Resultados: a abordagem do tema do aborto na graduação é limitada, pois foi ensinado em poucos momentos e como morbidade do ciclo gravídico-puerperal. As enfermeiras se sentem despreparadas para assistirem as mulheres no aborto legal. Conclusão: o tema do aborto apresenta uma abordagem restrita para a formação da consciência crítico-reflexiva e parece favorecer a reprodução do senso comum sobre o aborto.
\end{abstract}

Descritores: Aborto; saúde da mulher; enfermagem; educação em enfermagem.

\section{ABSTRACT}

Objective: to describe the approach to the subject of abortion in undergraduate education and its relation with critical education from the perspective of newly graduated nurses. Method: qualitative study carried out with 26 newly graduated nurses and enrolled in residency programs in the city of Rio de Janeiro. Individual interviews took place from April to July 2016 , being analyzed by dialectic hermeneutics and under Paulo Freire's perspective. The study was approved by Ethics Research Committee. Results: The subject of abortion has a limited approach in undergraduate education. It was taught in few moments and as morbidity factor during pregnancy-puerperal cycle. Nurses feel unprepared to assist women in legal abortion. Conclusion: the restricted approach to the topic of abortion means a poor contribution to a critical-reflexive awareness and seems to favor the reproduction of common sense about abortion.

Descriptors: Abortion; women's health; nursing; nursing education.

\section{RESUMEN}

Objetivo: describir el enfoque del tema del aborto en la enseñanza de la graduación y sus nexos con la formación crítica en la perspectiva de las enfermeras recién graduadas. Método: investigación cualitativa realizada con 26 enfermeras recién graduadas y matriculadas en programas de residencia en el municipio de Rio de Janeiro. Las entrevistas individuales ocurrieron en el período de abril a julio de 2016, siendo analizadas por la hermenéutica dialéctica y con base referencial de Paulo Freire. El estudio respetó las normas éticas y fue aprobado poor comite de ética. Resultados: el abordaje del tema del aborto en la graduación es limitado, pues fue enseñado en pocos momentos y como morbilidad del ciclo embarazo-puerperio. Las enfermeras se sienten despreparadas para asistir a las mujeres en el aborto legal. Conclusión: el tema del aborto presenta un abordaje restringido para la formación de la conciencia crítico-reflexiva y parece favorecer la reproducción del sentido común sobre el aborto.

Descriptores: Aborto; salud de la mujer; enfermeira; educación en enfermería

\section{INTRODUÇÃO}

O aborto é uma das principais causas de morte materna no Brasil e a interrupção voluntária da gravidez está prevista em lei apenas para os casos de risco de vida da mulher, estrupo e anencefalia fetal. Estimam-se que 416 mil mulheres abortaram somente no ano de 2015 , sendo que a metade dessa totalidade fez uso de medicamentos para abortar e quase cinquenta por cento dessas mulheres ficaram internadas para finalizar o aborto ${ }^{1}$.

Essas restrições no acesso ao aborto legal impelem as mulheres com gravidez indesejada a recorrerem ao aborto inseguro em locais clandestinos. Quando há complicações, elas recorrem aos serviços de saúde e, conforme a gravidade, podem levá-las ao óbito ${ }^{2}$. Além do risco à vida, essas mulheres apresentam sofrimento psicofísico consequente à clandestinidade, julgamento social e criminalização, bem como enfrentam atitudes profissionais de pouco acolhimento, discriminatórias e, por vezes, punitivas ${ }^{3}$.

'Enfermeira. Mestre. Universidade do Estado do Rio de Janeiro. Rio de Janeiro, Brasil. E-mail: mariana.uerj.2010.1@gmail.com

"Enfermeira. Doutora. Professora Adjunta. Universidade do Estado do Rio de Janeiro. Rio de Janeiro, Brasil. E-mail: adrianalenho.uerj@gmail.com

I'Artigo extraído da dissertação intitulada: A temática do abortamento no ensino de enfermagem: entre o senso comum e a consciência crítica. Programa de Pós-Graduação em Enfermagem. Universidade do Estado do Rio de Janeiro. 2017. 
Frente a esse importante problema de saúde pública, espera-se que a formação promova nos futuros profissionais a compreensão da complexidade de aspectos envolvidos na problemática do aborto; atitudes de respeito aos direitos humanos, sexuais e reprodutivos, e competências para o cuidado qualificado, integral e humano ${ }^{4}$.

Portanto, os cursos de graduação em saúde e enfermagem devem estimular seus alunos a refletirem criticamente sobre as questões em torno do aborto e adotar estratégias pedagógicas que viabilizem a superação das contradições entre o que se espera na formação profissional e a realidade da assistência à mulher em situação de aborto ${ }^{3-4}$.

Ao considerar a problemática descrita e que a formação do pensamento crítico na graduação potencializa as habilidades técnico-científicas, éticas e humanísticas indispensáveis ao cuidado de enfermagem, elaborou-se a seguinte questão norteadora: Como o tema do aborto foi abordado no ensino do curso de graduação na visão das enfermeiras recém-graduadas?

A pesquisa objetivou descrever a abordagem do tema do aborto no ensino da graduação e seus nexos com a formação crítica na perspectiva das enfermeiras recém-graduadas.

O presente estudo se justifica pela possibilidade de ampliar a compreensão sobre o ensino do tema do aborto na graduação, a fim de contribuir com a reflexão sobre sua abordagem pedagógica com referência à formação crítica sobre o tema e, indiretamente, favorecer a melhoria da assistência às mulheres em situação de aborto.

Para alcançar tal propósito, elegeu-se o referencial teórico da educação crítica, especificamente os conceitos pedagógicos de Paulo Freire sobre a formação crítica-reflexiva, que serão apresentados a seguir.

\section{REFERENCIAL TEÓRICO}

O ensino de enfermagem tem sido influenciado pelas correntes educacionais progressistas que propõem a problematização da realidade, a fim de promover a autonomia do educando na construção do conhecimento e atender às Diretrizes Curriculares Nacionais, que preconizam a formação generalista, humanista, crítica e reflexiva ${ }^{5}$.

Entre essas correntes educacionais, destaca-se o pensamento pedagógico de Paulo Freire, que teorizou sobre o diálogo e ação reflexiva no processo educativo. A ação reflexiva é necessária para o processo de conscientização sobre si e sobre o mundo, e se dá por meio da transitividade da consciência. Esta passa a se transitivar quando há ampliação do diálogo com as outras pessoas e com o mundo. Inicialmente, passa pela fase da transitividade ingênua, quando a consciência ainda guarda simplicidade na interpretação dos problemas e a visão de mundo é conformada pelas ideias, crenças e valores da cultura dominante ${ }^{6}$.

Quando a consciência alcança a transitividade crítica, a pessoa é capaz de ultrapassar a superfície dos fenômenos e viabiliza a profundidade na interpretação dos problemas, necessária para exercer a responsabilidade social e política, e perceber-se com compromisso ético de respeito à dignidade e à autonomia humana. Assim sendo, a educação tornase libertária e humanizadora ${ }^{6-7}$.

A educação deve disponibilizar aos alunos informações consistentes e significativas para a construção dos conhecimentos, mediante o diálogo e o entendimento dos problemas e conflitos envolvidos na realidade em análise. Desse modo, os alunos podem desenvolver sociabilidades resistentes à lógica dominante que intenta conformar as consciências para a aceitação das contradições sociais ${ }^{8-9}$.

Portanto, a pedagogia freireana tem como valor intrínseco a humanização, pois desenvolve a capacidade inerente do humano de compreender essas contradições e adotar atitudes críticas, amorosas e capazes de superar os mecanismos da opressão social e, portanto, geradores da violência na sociedade ${ }^{8-9}$.

Nessa perspectiva educacional, o futuro profissional tem condições de superar o senso comum, atuar na mudança da realidade de iniquidades e discriminações que as mulheres em situação de aborto sofrem, que são resultantes de um contexto social eivado de valores morais, religiosos e culturais. Somado a isso, há questões de gênero subjacentes que determinam diferenças nos papéis, normas, comportamentos e atributos do feminino e do masculino. Pois, em cada caso de aborto, há um homem envolvido e corresponsável pela concepção ${ }^{3-4}$.

Portanto, o ensino do tema do aborto na graduação em enfermagem deve considerar as diversas facetas deste fenômeno e propiciar a reflexão crítica sobre os seus determinantes sociais e as iniquidades associadas ao gênero, a fim de viabilizar a formação profissional humanista, reflexiva e crítica ${ }^{3-5}$.

\section{METOdologia}

Pesquisa qualitativa realizada com enfermeiras recém-graduadas e vinculadas a quatorze programas de residência de uma Instituição de Ensino Superior (IES) pública, sediados em hospital de ensino, unidades da saúde da família e maternidades públicas situadas no município do Rio de Janeiro. 
As participantes foram vinte e seis enfermeiras que cursavam o primeiro ano do programa de residência. Este grupo foi considerado prioritário para o estudo por ter um perfil predominante de profissionais recém-graduados e, portanto, as lembranças sobre o ensino no curso de graduação estão mais vívidas, o que favoreceu o alcance do objetivo da pesquisa aqui descrita.

Por ser um grupo constituído majoritariamente por mulheres, visto que apenas dois eram homens, optou-se pela designação pelo sexo predominante, como enfermeiras, bem como pelo atributo distintivo de seu perfil profissional, recém-graduadas.

Estas enfermeiras foram selecionadas de modo intencional, a partir de um grupo elegível de 115 enfermeiras que cursavam o primeiro ano dos quatorze programas de residência no ano de 2016 . As participantes incluídas na pesquisa atenderam aos seguintes critérios de inclusão: ser enfermeira regularmente matriculada em programa de residência, estar cursando o primeiro ano do programa e ter concluído o curso de graduação em enfermagem entre janeiro de 2015 e fevereiro de 2016. As excluídas foram as enfermeiras residentes em afastamento ou licenciadas durante o período de coleta de dados, que ocorreu no período de abril a julho de 2016.

Como estratégia de coleta de dados, as enfermeiras elegíveis foram convidadas a participar da pesquisa nos intervalos ou ao final das aulas teóricas de seus programas de residência na IES. Aquelas que demonstraram interesse em participar do estudo e atenderam aos critérios de inclusão foram contatadas para agendamento das entrevistas nos dias das aulas, em um local reservado, e com observância da diversidade das áreas de formação na residência, como o segmento da saúde da família; o segmento clínico-cirúrgico, representado pelas especialidades clínicas, cirúrgicas e de terapia intensiva; e o segmento materno-infantil, concernente às especialidades da área obstétrica, pediátrica e neonatal.

As entrevistas foram individuais, gravadas e orientadas por um roteiro semiestruturado, previamente testado, constituído por sete perguntas destinadas à caracterização das participantes e dezesseis questões abertas concernentes ao objeto de pesquisa.

Após a transcrição, os depoimentos foram analisados por meio da hermenêutica-dialética, método que conjuga a fase hermenêutica - visando à compreensão dos sentidos e significados que emergem dos textos, narrativas, entrevistas e outros documentos - com a fase dialética, que intenta a análise da crítica destes sentidos e significados a fim de buscar suas ambivalências, incompletudes, dissensos e núcleos contraditórios, bem como suas relações com o contexto social ${ }^{10}$.

Os passos operacionais desta análise são: a) ordenação dos dados, com leitura exaustiva dos conteúdos transcritos; b) classificação dos dados, buscando-se revelar as ideias centrais sobre o objeto de estudo por meio do agrupamento temático e a partir dos sentidos e significados comuns; e c) análise final, quando o movimento dialético se estabelece entre o material empírico e a perspectiva teórica do estudo, possibilitando a elaboração das sínteses interpretativas ${ }^{10}$.

A pesquisa respeitou as normas éticas de pesquisa envolvendo seres humanos, obtendo o Protocolo $\mathrm{n} 01.533 .584$ e CAAE no 52508915.8.0000.5282. Optou-se por adotar codificações para manter o anonimato das participantes por meio da letra $E$, seguida da ordem de concessão das entrevistas, como E1, E2, E3, e assim por diante.

\section{RESULTADOS}

As vinte e seis enfermeiras participantes da pesquisa têm a idade média de 25,3 anos, com variação etária de 22 a 40 anos, e são procedentes de cursos de graduação em enfermagem de doze IES, sendo dez sediadas no estado do Rio de Janeiro, públicas e privadas, e as demais são IES públicas localizadas em Minas Gerais e no Rio Grande do Sul. Houve predomínio das enfermeiras egressas dos cursos de graduação ofertados por IES pública (19) e daquelas que concluíram o curso de graduação no ano de 2015 (20).

Quanto aos segmentos especializados da residência, doze enfermeiras cursavam o primeiro ano dos programas das áreas de enfermagem obstétrica, pediátrica e neonatal; oito participantes estavam se especializando nas áreas de enfermagem clínica, cirúrgica e de terapia intensiva, e seis enfermeiras eram do programa da saúde da família.

A seguir, são descritas as duas categorias que emergiram do processo de análise hermenêutica-dialética.

\section{A abordagem superficial do tema aborto no ensino da graduação em enfermagem}

As enfermeiras recém-graduadas consideram que o tema aborto foi pouco abordado no curso de graduação em enfermagem, sendo este ministrado principalmente na disciplina de saúde da mulher e com enfoque na morbidade do ciclo gravídico-puerperal: 
Eu acho que é um tema pouco abordado ainda [...]. Isso tinha que ser mais abordado dentro de sala de aula, até para os próximos profissionais terem mais ciência desde o início da graduação e não somente em uma disciplina [...]. (E9)

Mais nesse sentido fisiopatológico [...] ou ainda essa questão da saúde pública [...] da moça ir atrás [do aborto inseguro], [...] e não tanto pela questão psicológica [...], se ela quer ou não essa gestação. Isso não foi muito bem tratado. (E2)

A abordagem do tema aborto na perspectiva clínica foi percebida pelas entrevistadas como uma estratégia para minimizar as possíveis polêmicas suscitadas pelo tema em sala de aula. A problemática da clandestinidade também foi pouco discutida durante as aulas da graduação:

Na verdade, eu sentia que as pessoas [docentes] tinham um certo receio de tocar nesse assunto por toda a polêmica que ele poderia causar pela religião de muitos alunos que não concordavam. (E7)

Falavam [os docentes] sobre o aborto relacionado ao tratamento e voltado para o aborto espontâneo. Nunca do aborto induzido, mas sempre do aborto espontâneo [...]. (E17)

As participantes mencionaram pouco destaque nas aulas para as situações de aborto legal e o papel profissional da enfermagem nessa assistência:

Não lembro de ter abordado isso [o aborto legal]. Eu não sei se não foi, mas eu não lembro. Inclusive eu não sei qual é o papel do enfermeiro no aborto legal. (E4)

Apesar dessas limitações no ensino sobre o tema do aborto, um segmento das participantes mencionou que teve aulas com metodologia problematizadora e com enfoque nas questões do gênero feminino:

Com imparcialidade, isso eu me lembro bem [...]. É ter um olhar diferente para essas mulheres [...] acolher e de tentar entender e ajudar. (E26)

Antes de falar em si do abortamento, teve uma inserção na característica de gênero e de opressão por ser mulher [...]. Eles [docentes] queriam que tivéssemos uma reflexão crítica sobre esse assunto e do tipo de profissional que gostaríamos de ser como enfermeiros. (E1)

\section{As concepções ambivalentes das enfermeiras recém-graduadas sobre o aborto}

As enfermeiras recém-graduadas expressam a influência dos valores morais e uma visão estereotipada sobre o atendimento da mulher em situação de aborto, como denotam as seguintes falas:

Ah, eu acho que desde o momento da fecundação há vida. Desde que há embrião já é aborto, não importa a idade gestacional [...]. (E12)

Eu só acho que não é legal legalizar o aborto [...], a partir do momento que você chega lá e conta uma história e diz que foi violentada, eles não perguntam nada, simplesmente executam o aborto. (E26)

Ao se colocarem como profissionais que podem atuar na assistência da mulher que tem direito ao aborto legal, as enfermeiras expressaram seus conflitos morais no cuidado dessas mulheres:

Eu não sei se eu como profissional, se fosse uma situação [aborto] legal, [...] mas praticar o aborto, para mim, vai contra algumas leis, principalmente contra a lei da reencarnação [...]. Também não sei se eu tenho direito de negar a fazer [participar do procedimento] se chegar alguma situação dessa para mim no serviço de saúde (E11).

Apesar dessas influências e conflitos, um segmento das participantes reconhece que os direitos da mulher devem ser respeitados e que o aborto deve ser visto como um problema de saúde pública:

o aborto deveria ser mais visto como uma causa evitável de morte se fosse mais discutido. (E15)

A mulher tem os seus motivos, ela tem o seu contexto e a gente tem que apoiar. [...] Eu acho que o governo, o Estado, tem que dar todo esse aparato para essa mulher. (E17)

Como recém-graduadas, elas se consideram despreparadas para atuar na assistência à mulher em situação de aborto e atribuem o seu despreparo à abordagem desatualizada do tema no ensino da graduação:

Eu acho que não saí preparada o suficiente da graduação para lidar com essa temática, definitivamente não saí mesmo. (E12)

$O$ ensino deixou de abordar a atualidade. Agora, está muito em foco o feminismo e tem muitas mulheres lutando por esse direito [ao aborto] [...]. Eu acho que [o ensino] foi meio arcaico. (E13)

\section{DISCUSSÃO}

De início, apontam-se as limitações da pesquisa por focalizar a visão de um grupo particular de enfermeiras recémgraduadas, por não contemplar a perspectiva docente e incluir outras técnicas metodológicas que possibilitariam ampliar a compreensão do fenômeno aqui estudado. 
Apesar desses limites, a pesquisa revelou que o tema do aborto foi pouco abordado nas aulas do curso de graduação para as participantes da pesquisa. Esse pouco destaque também foi observado na análise dos programas de disciplinas da graduação em enfermagem de universidades públicas, o que pode denotar uma tendência de silenciamento dessa temática no ensino da enfermagem ${ }^{11}$.

A seleção de conteúdos curriculares não é uma opção neutra ou desprovida de intencionalidade, mesmo quando se pensa que a ação pedagógica decorre de uma suposta neutralidade política. O currículo é uma produção cultural e, como tal, há tensões e negociações produzidas no âmbito das relações sociais, de saberes e de poderes que o constitui epistemologicamente. Portanto, implica numa seletividade de discursos e saberes que são negociados, debatidos, consensuados e, por fim, legitimados, fazendo com que outras posições ou perspectivas sejam negadas ou apagadas do repertório curricular ${ }^{12}$.

Além do apagamento do tema do aborto no repertório curricular da graduação, verificou-se também a tendência de ser ensinado com base no modelo biologicista fragmentado e sem ênfase para as questões sociopolíticas, emocionais e de gênero associadas ao fenômeno do aborto ${ }^{3}$. Essa perspectiva restrita do ensino prejudica a ação reflexiva necessária para a compreensão das realidades social, histórica e cultural que permeiam a saúde das mulheres em situação de aborto, bem como das questões do gênero feminino subjacentes à saúde sexual e reprodutiva ${ }^{13}$.

Tal restrição no ensino favorece a reprodução do pensamento vulgar e irrefletido sobre a questão, denominado senso comum, e a permanência dos preconceitos, estereótipos e discriminações com que as mulheres se deparam na sociedade e nos serviços de saúde, podendo prejudicar e desumanizar a assistência prestada ${ }^{14}$.

O ensino de enfermagem também se mostrou limitado quanto à formação para o cuidado das mulheres no aborto legal segundo as enfermeiras recém-graduadas, o que desfavorecer atitudes defensoras dos direitos femininos e da mudança da realidade adversa que elas vivenciam nos serviços de saúde ${ }^{13}$.

Destaca-se que o estupro é o principal motivo dos atendimentos de aborto previsto em lei no Brasil, correspondendo a $94 \%$ no período de 2013 a $2015^{15}$. Apesar desse triste cenário, verificam-se inadequações nos serviços de saúde frente às normas técnicas, desconhecimento da legislação pelos profissionais e manifestações de objeção de consciência para realizar o procedimento ${ }^{16}$.

Portanto, a resposta da enfermagem frente à magnitude e à perversidade dessa violência de gênero pode ser limitada em virtude do modo como esse assunto vem sendo conduzido em sala de aula, fazendo que suas alunas tenham limitada reflexão sobre os determinantes dessa realidade, suas formas de enfrentamento e as implicações para o exercício da profissão, além de favorecer a persistência dos valores morais e religiosos dominantes e do olhar ingênuo sobre os ditames e as consequências das premissas da sociedade conservadora ${ }^{17}$.

A abordagem da temática do aborto na graduação também é influenciada pela educação tradicional, mas os depoimentos lançam luz sobre outras perspectivas pedagógicas que problematizam o tema e visam a despertar a reflexão nas discentes sobre as questões éticas, de gênero e relativas ao papel profissional. O desvelamento crítico das questões subjacentes ao fenômeno do aborto pode ampliar a percepção da realidade e levar à superação das restrições na formação de enfermagem aqui reveladas.

Contudo, a percepção do real só se efetiva quando o olhar ingênuo é ultrapassado e a realidade concreta é compreendida para a construção de uma outra realidade com bases democráticas. Não se pode ser neutro frente ao mundo e à desumanização, há que se fazer uma opção, ou se adere à mudança que vai ao encontro da verdadeira humanização do ser humano, ou se fica a favor da permanência do que desumaniza o mundo, como adverte Paulo Freire ${ }^{7}$.

\section{CONCLUSÃO}

Há limitações na abordagem do tema do aborto no ensino da graduação em enfermagem, tanto em relação ao número de aulas destinadas ao tema durante a graduação, quanto pelo modo tradicional com que o assunto é conduzido pedagogicamente pelos docentes. Estas limitações favorecem a persistência da influência dos valores morais conservadores sobre as alunas e causam nelas conflitos entre as suas crenças pessoais e o seu papel profissional, fazendo com que se percebam despreparadas para atuar no atendimento das mulheres em situações de aborto previstas em lei.

Apesar dos relatos sobre a perspectiva educativa problematizadora, o ensino na graduação em enfermagem parece propiciar a persistência do olhar ingênuo e a reprodução do senso comum sobre o aborto, sendo restrito para a formação da consciência crítico-reflexiva nas discentes.

Sugere-se ampliar os estudos sobre o ensino do tema do aborto e suas interfaces com a atuação da enfermagem neste importante problema de saúde no país. 


\section{REFERÊNCIAS}

1. Diniz D, Medeiros M, Madeiro A. National Abortion Survey 2016. Ciênc. saúde coletiva [Internet], 2017 [cited 2018 Mar 5]; 22(2):653-60. DOI: http://dx.doi.org/10.1590/1413-81232017222.23812016

2. Faúndes A, Miranda L. Ethics surrounding the provision of abortion care. Best Pract Res Clin Obstet Gynaecol [Internet], 2017 [cited 2018 Mar 5]; 43: 50-57. DOI: https://doi.org/10.1016/j.bpobgyn.2016.12.005

3. Lemos A, Russo JA. Healthcare professionals and abortion: what is said and not said in a professional healthcare capacitation. Interface (Botucatu) [Internet], 2014 [cited 2018 Jul 1];18(49):301-12. DOI: http://dx.doi.org/10.1590/1807-57622013.0754

4. Santos DLA, Brito RS. Women's feelings on the occurrence of induced abortion. Rev enferm UERJ [Internet], 2016 [cited 2018 Jul 02]; 24(5):e15613. DOI: http://dx.doi.org/10.12957/reuerj.2016.15613

5. Pires AS, Souza NVDO, Penna LG, Tavares KFA et. al. Undergraduation in the nursing school: an integrative review of literature. Rev enferm UERJ [Internet], 2014[cited 2018 Jul 02]; 22(5):705-11. DOI: http://dx.doi.org/10.12957/reuerj.2014.11206

6. Freire P. Conscientização. 4 ed. São Paulo: Cortez, 2016.

7. Freire P. Educação e Mudança. 36ạ ed. Rio de Janeiro: Paz e Terra, 2011

8. Freire P. Educação como prática da liberdade. 36. ed. Rio de Janeiro: Paz e Terra, 2014.

9. Costa BB. Paulo Freire: educator-thinker of liberation. Pro-Posições [Internet], 2016[cited 2018 Jul 3]; 27(1): 93-110. DOI: http://dx.doi.org/10.1590/0103-7307201607906

10. Minayo MCS. O desafio do conhecimento: pesquisa qualitativa em saúde. 14ạ ed. São Paulo: HUCITEC; 2014

11. Marconsin MN, Marçal M, Xavier J, Silva LR, Lemos A. The abortion issue in undergraduate nursing and medicine. Saúde Transform. Soc [Internet], 2013 [cited $2018 \mathrm{Jul}$ 3];4(3):58-64. Available from: http://incubadora.periodicos.ufsc.br/index.php/saudeetransformacao/article/view/1991

12. Carvalho FA, Polizel AL, Maio ER. A school with no political party: discursivity, curriculum and social movements. Semina Cienc Soc Hum. [Internet], 2016 [cited 2018 Jul 8]; 37(2): 193-210. DOI: http://dx.doi.org/10.5433/1679-0383.2016v37n2p193

13. Brito RS, Santos DLA, Gama CMS, Silva AB. Opinion of nurses' students on induced abortion. Rev. baiana enferm. [Internet] 2015 [cited 2018 Jul 10]; 29(2): 115-24. DOI: http://dx.doi.org/10.18471/rbe.v29i2.12899

14. Magagnin AB, Aires LCP, Freitas MA, Heidemann ITSB, Maia ARC. The nurse as a political-social being: perspectives of a professional in transformation. Cienc Cuid Saúde [Internet], 2018 [cited 2018 Jul 10]; 17(1):1-7. DOI: http://dx.doi.org/10.4025/cienccuidsaude.v17i1.39575

15. Madeiro AP, Diniz D. Legal abortion services in Brazil - a national study. Ciênc. saúde coletiva [Internet], 2016 [cited 2018 Jul 15]; 21(2):563-72. DOI: http://dx.doi.org/10.1590/1413-81232015212.10352015

16. Silva EF, Trevisan DC, Lorenzini E, Pruss ACF, Strapasson MR, Bonilha ALL. Attention to woman in case of induced abortion: the perception of professional nursing. Rev Enferm UFSM [Internet], 2015 [cited 2018 Jul 15];5(3):454-64. DOI: http://dx.doi.org/10.5902/2179769214801

17. Machado LZ. Abortion as a right and abortion as a crime: the neoconservative setback. Cad Pagu. [Internet], 2017 [cited 2018 Jul 15]; 50: e17504. DOI: https://dx.doi.org/10.1590/18094449201700500004 